\title{
COMPARAÇÕES ENTRE AS PROPRIEDADES QUÍMICAS DE SOLOS DAS REGIÕES DA FLORESTA AMAZÔNICA E DO CERRADO DO BRASIL CENTRAL
}

\author{
J.L.I. DEMATTÉ; J.A.M. DEMATTÊ \\ Departamento de Ciencia do Solo - ESALQ/USP, C.P. 9 - CEP: 13418-900-Piracicaba,SP
}

\begin{abstract}
RESUMO: Foi estudada uma série de propriedades dos solos das regiōes Amazônica e de cerrado. Para a região de cerrado, selecionou-se 17 perfis do Triângulo Mineiro, 6 perfis da região de Goiás e 5 perfis do Sudeste de MT, todos publicados em boletins de solo da EMBRAPA, sendo a maioria latossolos. Na Amazónia, selecionaram-se dados dos Boletins do Projeto RADAM BRASIL, sendo 76 perfis ao todo, retirados desde a região do Pará até o Acre; destes, 38 são latossolos e 38 podzólicos vermelho amarelo (PVA). Para fins de comparação entre os solos as seguintes profundidades foram padronizadas: $0-10 \mathrm{~cm} ; 10-40 \mathrm{~cm} ; 40-80 \mathrm{~cm} ; 80-100 \mathrm{~cm}$. Não foi considerada a camada de serapilheira. Os solos da regiāo do cerrado são mais intemperizados do que os da região Amazônica, havendo dominância de mineralogia oxídica, mais estável do que a dos solos da região Amazônica, onde a mineralogia é caulinitica com contribuição de minerais $2: 1$. Apesar disso, a CTC dos latossolos da Amazônia não difere da CTC dos solos de cerrado. Na região Amazónica os latossolos apresentam Ki diferenciado, sendo um grupo de solos com Ki na faixa de 0,8-1,5 típico dos latossolos e um grupo na faixa de 2,0-2,2. O grupo dos PVA possui Ki superior a 2,0. Na região de cerrado o Ki varia de 0,6 a 1,5. Os solos da região Amazônica são mais ácidos e apresentam valores de Al trocável significativamente superiores do que os da região de cerrado, o que requer mais corretivos de que o Cerrado. Há grande diferença entre a saturação por bases (V) e o pll nos solos das duas regiōes. Na regiāo Amazónica a elevação do pH segue a elevaçāo do $\mathrm{V}$ enquanto que no cerrado isto não ocorre. Em consequência deste fato, o manejo químico em relação à quantidade de calcário deve ser diferenciado entre as regiōes. 0 teor de carbono orgânico nos solos de textura arenosa, a média é sempre maior para a regiāo Amazônica. Entretanto, para todas as profundidades estudadas e para os solos argilosos a muito argilosos, o teor de carbono organico é sempre mais elevado na região de cerrado. Não houve diferenças significativas entre o teor de carbono orgânico dos solos com vegetação de cerrado e cerradão. Por outro lado, o teor de carbono orgânico dos latossolos da regiāo Amazônica é mais elevado do que dos PVA.
\end{abstract}

Descritores: Amazónia, Brasil Central, cerrado, propriedades químicas.

\section{COMPARISONS OF CHEMICAL PROPERTIES OF FOREST (AMAZON REGION) AND SAVANNA SOILS (CENTRAL REGION) OF BRAZIL}

\begin{abstract}
Chemical properties were studied in soil samples from two main fisiographic regions of Brazil: the Amazon region represented by the tropical rain forests and the Brazilian central region represented by the savanna (cerrado) vegetation. For this study 17 profiles were selected from the Triangulo Mineiro area: 6 profiles from Goias state, and 5 profiles from the south eastern part of the Mato Grosso State. Most of the profiles are oxisols from medium to clayey texture. For the Amazon region 76 profiles were selected (38 oxisols and 38 ultisols) located from Para to Acre States. The following depths were selected: $0-10 \mathrm{~cm} ; 10-40 \mathrm{~cm} ; 40-80 \mathrm{~cm}$ and $80-100 \mathrm{~cm}$. The litter layer was not studied. The savanna region has soil in a more advanced weathered stage than the Amazon region. The Ki index of savanna soils varies from 6.0 to 1.5 and of Amazon soils the variation is from 1.3 to 2.5 that included Oxisols (Ki from 1.3 to 2.0) and Ultisols (Ki above 2.0). This indicates that the clay mineralogy of savanna soils is represented by an oxidic mineralogy that is more stable than in the Amazon region represented by a caulinitic mineralogy with 2:1 contribution. The Amazon soils are more acid and present exchangeable Al in higher amounts than savanna soils with a direct effect on chemical management. Soils pH correction requires more lime in Amazon soils than in the savanna. The are great differences in both regions between base saturation and pH index. In Amazon soils the pH increase follows the base saturation while this does not occur in savanna soils. In sandy soils the organic carbon is higher in Amazon for all depths studied. In soils with more than 35\% clay, the organic carbon is higher in savanna soils when all the depths are considered. There are no diferences between organic carbon in "cerrado" and "cerradão" (shot savanna and true savanna). Oxisols of the Amazon region have higher amounts of organic carbon than Ultisols.
\end{abstract}

Key Words: Amazonia, Central Brazil, cerrado, chemical properties. 


\section{INTRODUÇÃO}

A região Amazônica, com seus 4,8 milhões de $\mathrm{km}^{2}$, apresenta em torno de $50 \%$ de latossolos sendo seguido pelos solos podzolizados na faixa dos 30-35\% (DEMATTÊ, 1988). As atividades de exploração agrícola nesta região não tem feito distinção entre tais solos, principalmente as atividades de pecuária. Nos últimos 30 anos, aproximadamente $25 \%$ das áreas exploradas com pecuária foram degradadas e semi-abandonadas. As principais causas para a degradação, são consequência do desconhecimento das reações do meio ambiente a esta atividade, e na baixa fertilidade dos solos, em gramíneas inadequadas e no sistema de manejo inapropriada das pastagens (SERRÃO et al., 1979). Grande parte dos sistemas de agricultura, em larga escala, não estão tendo sucesso nesta região.

Por outro lado a área do cerrado com 1,8 milhões de $\mathrm{km}^{2}$, representada pelas regiões do Brasil Central e Centro Oeste, é hoje responsável pela produção de $35 \%$ de grãos do país (soja e milho) e com uma pecuária em franca evolução. Os solos desta região são predominantemente latossolos, cerca de $85 \%$ da área, de baixa fertilidade.

Não se tem conhecimento de áreas abandonadas por degradação nas mesmas proporções que tem ocorrido na Amazônia: a agricultura está tendo muito mais êxito na região de cerrado do que na região Amazônica.

Razões para tais diferenças, entre as duas regiões, são as mais diversas, mas sem dúvida, os solos tem muito a ver com isso. apesar destas regiões predominarem latossolos de textura média a argilosa, existem importantes diferenças entre suas propriedades.

O objetivo deste trabalho é o de comparar diversas propriedades dos solos destas duas áreas. Além disso, pretende-se estudar, com mais detalhes, as variações das propriedades dos solos dentro de uma mesma região. Com isso, espera-se melhor entender os solos destas regióes, e se possível, fornecer subsídios para um manejo mais adequado.

\section{MATERIAL E MÉTODOS}

\section{Regiōes e solos estudados}

Para a região de cerrado com regime ústico de umidade foram selecionados 17 perfis do
Triângulo Mineiro (EMBRAPA, 1982a), 6 perfis da região de Goiás (EMBRAPA, 1983) e 5 perfis do Sudeste de Mt (EMBRAPA, 1982b), todos classificados como latossolos distróficos ou álicos. Destes perfis, foram selecionados seis com vegetação de "cerradão", quatorze com vegetação de "cerrado" e oito com vegetação de "campo". A região estudada tem um regime de temperatura isohipotermico.

No caso da região Amazônica, foram selecionados ao todo, 76 perfis sendo, 38 de latossolos e 38 de podzólico vermelho amarelo, todos eles extraídos do PROJETO RADAMBRASIL. A relação das regiões estudadas, o número de perfis e a referência bibliográfica estão na Figura 1.

Os latossolos e os podzólicos são distróficos ou álicos, com exceção de dois perfis, que são eutróficos.

\section{Seleção da profundidade estudada}

Para fins de comparação entre os solos estudados, foi necessário padronizar as seguintes profundidades médias:

Profundidade 1 - de 0 a $10 \mathrm{~cm}$

Profundidade 2 - de 10 a $30 \mathrm{~cm}$

Profundidade 3 - de 30 a $60 \mathrm{~cm}$

Profundidade 4 - de 60 a $100 \mathrm{~cm}$

No primeiro caso, as profundidades de 0 5 e $0-15 \mathrm{~cm}$ foram consideradas como pertinente à faixa de 0-10 $\mathrm{cm}$. Não foi considerada a serapilheira (camada orgânica), tanto para a região Amazônica como para a região de cerrado. No segundo caso, na faixa normal de 10 a $30 \mathrm{~cm}$ foi incluído horizonte com até $40 \mathrm{~cm}$; no terceiro caso, de 30 a $60 \mathrm{~cm}$, foi incluído horizonte com até 80 $\mathrm{cm}$; no quarto caso, foi incluído horizonte com até $120 \mathrm{~cm}$ de profundidade.

\section{Seleção das profundidades estudadas}

Para todos os perfis foram selecionadas as seguintes características: teor de argila, $\mathrm{pH}$ em $\mathrm{H}_{2} \mathrm{O}$ e $\mathrm{KCl}$, teor de $\mathrm{Al}$ (em m.eg/100g solo), capacidade de troca catiônica do solo, a pH 7,0 (em m.eg $/ 100 \mathrm{~g}$ solo); teor de carbono orgânico. $O$ índice Ki não foi determinado para todos os perfis estudados. Na região Amazônica, dos 76 perfis examinados, 22 não tinham determinações de $\mathbf{K i}$. $\mathrm{Na}$ região do cerrado, todos os perfis tinham Ki. 
O teor de argila foi correlacionado com o teor de carbono orgânico para as quatro profundidades, inclusive com profundidades acumuladas, isto é, $0-20 \mathrm{~cm} ; 0-60 \mathrm{~cm} \mathrm{e} 0-100 \mathrm{~cm}$. O pH em $\mathrm{H}_{2} \mathrm{O}$ foi correlacionado com o teor de alumínio e saturação em bases e o Ki foi correlacionado com a capacidade de troca catiônica.

$\mathrm{Na}$ região do Brasil Central também foram estudadas as variações das propriedades químicas, principalmente teor de matéria orgânica entre os tipos de cerrado, a saber: campo, cerrado e cerradão. Na região Amazônica, as comparações foram feitas entre os solos podzolizados e latossolos.

No caso da comparação entre a CTC e o $\mathrm{Ki}$, foi escolhida a camada de 80 a $100 \mathrm{~cm}$, para diminuir o efeito da matéria orgânica na CTC e isto somente para os solos de textura argilosa (teor de argila superior a $35 \%$ ).

$\mathrm{Na}$ eventualidade de se querer calcular a quantidade de matéria orgânica em $\mathrm{t} / \mathrm{ha}$, foram usados os seguintes valores de densidade do solo, a saber: para o solo muito argiloso (teor de argila superior a $60 \%$ ), um valor de $1,0 \mathrm{~g} / \mathrm{cm}^{3}$; para solo argiloso (teor de argila entre $35-60 \%$ ), um valor de $1,2 \mathrm{~g} / \mathrm{cm}^{3}$ e para solo de textura média (aqui considerado com teor de argila de 15 a $35 \%$ ), um valor de $1,5, \mathrm{~g} / \mathrm{cm}^{3}$.

\section{RESULTADOS E DISCUSSÃo}

\section{Teor de matéria orgânica}

Os valores para o carbono orgânico, correlacionados com o teor de argila das duas regiões estudadas e grupadas pelas profundidades, estão indicadas na Figura 2. Através da análise desta figura, observa-se:

- A correlação entre os teores de carbono orgânico e de argila para a região Amazônica é baixa, com grande dispersão dos pontos quanto comparada com a região do cerrado, onde o $r^{2}$ apresenta sempre valores superiores a 0,64 .

- Apesar da grande variação dos dados para a região Amazônica, há uma tendência do teor de carbono orgânico, de aumentar de acordo com o teor da argila, o mesmo ocorrendo na região dos cerrados, também observado por LEPSCH (1980).

- Na camada de 0-10 cm (Figura 2), o teor de carbono orgânico da região Amazônica é sempre superior ao da região do cerrado, na faixa de textura arenosa a argilosa do solo, sendo idêntica à muito argilosa. Os teores variam de $1,4 \%$ a $1,90 \%$ (TABELA 1). À medida que se aumenta a profundidade do solo (Figura $2 b$ ), o teor de carbono orgânico para os solos da região Amazônica, a partir de $40 \%-42 \%$ de argila (1\%) contra $0,8 \%$ para solos argilosos e 1,4 para 1,8 para solos muito argilosos (TABELA 1). Na profundidade de $40-80 \mathrm{~cm}$ (Figura $2 \mathrm{c}$ ), o teor ultrapassa o teor de carbono orgânico dos solos da região do cerrado, ultrapassa o teor de carbono dos solos da região Amazônica, na faixa dos $38-40 \%$ de argila. A mesma tendência é verificada na camada de $80-100 \mathrm{~cm}$ (Figura 2d).

- Quando se considera o somatório das camadas (Figura 3), ainda se verifica a elevada dispersão dos dados para a região Amazônica e o excelente $r^{2}$ para a região do cerrado. Para a profundidade 0-20 cm (Figura 3a), o $r^{2}$ para a região do cerrado é de 0,7 , passando para 0,8 nas demais profundidades (Figuras $3 \mathrm{~b}$ e $3 \mathrm{c}$ ).

- À medida que a profundidade do solo vai aumentando, o teor de carbono orgânico da região do cerrado mostra-se superior ao dos solos da região Amazônica, isto é válido para os solos de textura argilosa e muito argilosa. O teor de carbono orgânico na faixa de $0-100 \mathrm{~cm}$ é de $4,2 \%$ na região Amazônica, contra $5,8 \%$ na região de cerrado para os solos com teor de argila acima de $60 \%$ (TABELA 1). Nos solos de textura média a arenosa, o teor de carbono orgânico dos solos da Amazônia é sempre superior ao da região do cerrado, independentemente da profundidade.

Os resultados aqui analisados, não deixam de surpreender, pois, nos meios acadêmicos, sempre se considera que os solos da região dos cerrados, como tendo baixo teor de matéria orgânica (LOPES, 1983; MALAVOLTA; KLIEMANN, 1985), e os da região Amazônica, como tendo elevado teor (SANCHEZ, 1976; VIEIRA; SANTOS, 1987).

O teor de carbono orgânico do solo depende da relação bm/k (SANCHEZ, 1976), onde b representa o teor de carbono orgânico bruto depositado anualmente no solo, $m$ representa a taxa de conversão deste carbono orgânico bruto em carbono orgânico do solo e k representa a taxa de decomposição do carbono orgânico do solo. 


\begin{tabular}{|c|c|c|c|c|c|}
\hline Região & $\frac{\mathrm{N}^{\mathbf{0}} \mathrm{de}}{\text { Latossolo }}$ & $\frac{\text { Perfis }}{\text { PV }}$ & Referência & $\begin{array}{l}\text { Regime } \\
\text { Hídrico }\end{array}$ & $\begin{array}{l}\text { Regime } \\
\text { Térmico }\end{array}$ \\
\hline & \multicolumn{3}{|c|}{$\underline{\text { Reg. Amazônica }}$} & & \\
\hline \multicolumn{6}{|l|}{ Folha SC-22 } \\
\hline Tocantins & 7 & 3 & Radam Vol. 22 (1981) & Údico & Isotérmico \\
\hline \multicolumn{6}{|l|}{ Folha SC-20 } \\
\hline Porto Velho & 5 & 4 & Radam Vol. 16 (1978) & Údico & Isotérmico \\
\hline \multicolumn{6}{|l|}{ Folha SC-21 } \\
\hline$\underline{\text { Juruema }}$ & 5 & 4 & Radam Vol. 20 (1980) & Perúdico & Isotérmico \\
\hline \multicolumn{6}{|l|}{ Folha SA-21 } \\
\hline Santarém & 8 & 6 & Radam Vol. 10 (1976) & Údico & Isotérmico \\
\hline \multicolumn{6}{|l|}{ Folha SA-19 } \\
\hline Icá & 5 & 5 & Radam Vol. 14 (1977) & Perúdico & Isotérmico \\
\hline \multicolumn{6}{|l|}{ Folha SC-19 } \\
\hline$\underline{\text { Rio Branco }}$ & 3 & 9 & Radam Vol. 12 (1976) & $\begin{array}{l}\text { Údico, } \\
\text { Perúdico }\end{array}$ & Isotérmico \\
\hline Roraima & 5 & 7 & Radam Vol. 8 (1975) & Ústico & Isohipertérmico \\
\hline \multirow[t]{2}{*}{ Total Perfis } & 38 & 38 & & & \\
\hline & \multicolumn{5}{|c|}{ Reg. de Cerrado } \\
\hline Triângulo Mineiro & 17 & - & Embrapa 1982 & Ústico & Isohipertérmico \\
\hline Goiás & 6 & - & Embrapa 1983 & Ústico & Isohipertérmico \\
\hline Sudeste de MT & 5 & - & Embrapa 1982 & Ústico & Isohipertérmico \\
\hline
\end{tabular}

Figura 1. Relação das áreas estudadas das regiões Amazônica e do Cerrado, número de perfis, tipo de solo e os regimes de umidade e térmico.

Para a região Amazônica, o b é considerado 5 vezes superior ao da região do cerrado e m é considerado semelhante para os dois casos (GREENLAND \& NYE, 1959). O valor de $k$ para floresta tropical de ambiente ústico $\varepsilon$ para solos de textura média, a argilosa é de $2,5 \%$, enquanto que para o cerrado, também de ambiente ústico, de $1,3 \%$, praticamente duas vezes menor.

Foi observada uma grande dispersão dos resultados do carbono orgânico para a regiâo Amazônica, ilustrado pelo baixo valor de $r^{2}$. Isto se deve possivelmente ao fato desta matéria orgânica não estar ainda estabilizada e não ter por isso, atingido o estágio de equilíbrio motivado, provavelmente, pela grande variação climática, indo do ambiente ústico até o perúdico (Figura 1).

Isto pode ser verificado na Figura 2a., onde, para um mesmo valor de argila, digamos, $15 \%$, o teor de carbono varia de 0,3 a $3 \%$. 0 mesmo fato tem ocorrido nas demais profundidades, principalmente para as texturas mais arenosas (Figura 2). 
TABELA 1 - Variação do teor de carbono orgânico de acordo com a profundidade e o teor de argila das regiōes Amazônica e do Cerrado.

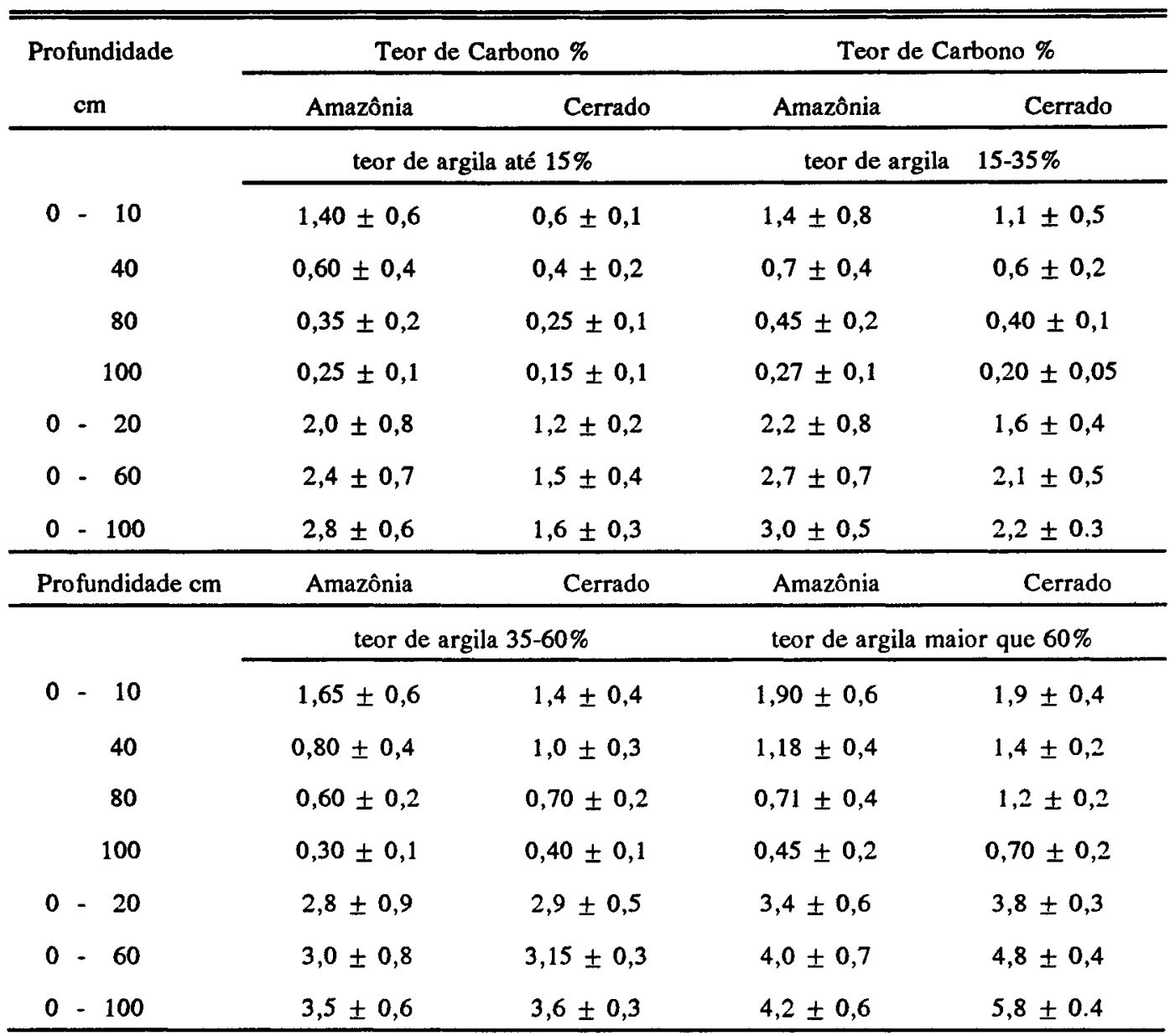

TABELA 2 - Teores de carbono orgânico em porcentagem dos latossolos e podzólico vermelho amarelo da região Amazônica.

\begin{tabular}{ccccc}
\hline \multirow{2}{*}{$\begin{array}{c}\text { Profundidade } \\
\mathrm{cm}\end{array}$} & \multicolumn{4}{c}{ Teor de Carbono Orgânico (\%) } \\
\cline { 2 - 5 } & Latossolo & PVA & Latossolo & PVA \\
\cline { 2 - 5 } $0-10$ & Teor de argila & $35-60 \%$ & \multicolumn{2}{c}{ Teor de argila maior que 60\% } \\
\cline { 2 - 5 } 40 & $2,1 \pm 0,3$ & $1,2 \pm 0,3$ & $2,3 \pm 0,4$ & $2,1 \pm 0,3$ \\
80 & $1,1 \pm 0,3$ & $0,7 \pm 0,3$ & $1,6 \pm 0,3$ & $0,9 \pm 0,3$ \\
100 & $0,9 \pm 0,2$ & $0,6 \pm 0,2$ & $1,5 \pm 0,2$ & $0,8 \pm 0,1$ \\
\hline \hline
\end{tabular}



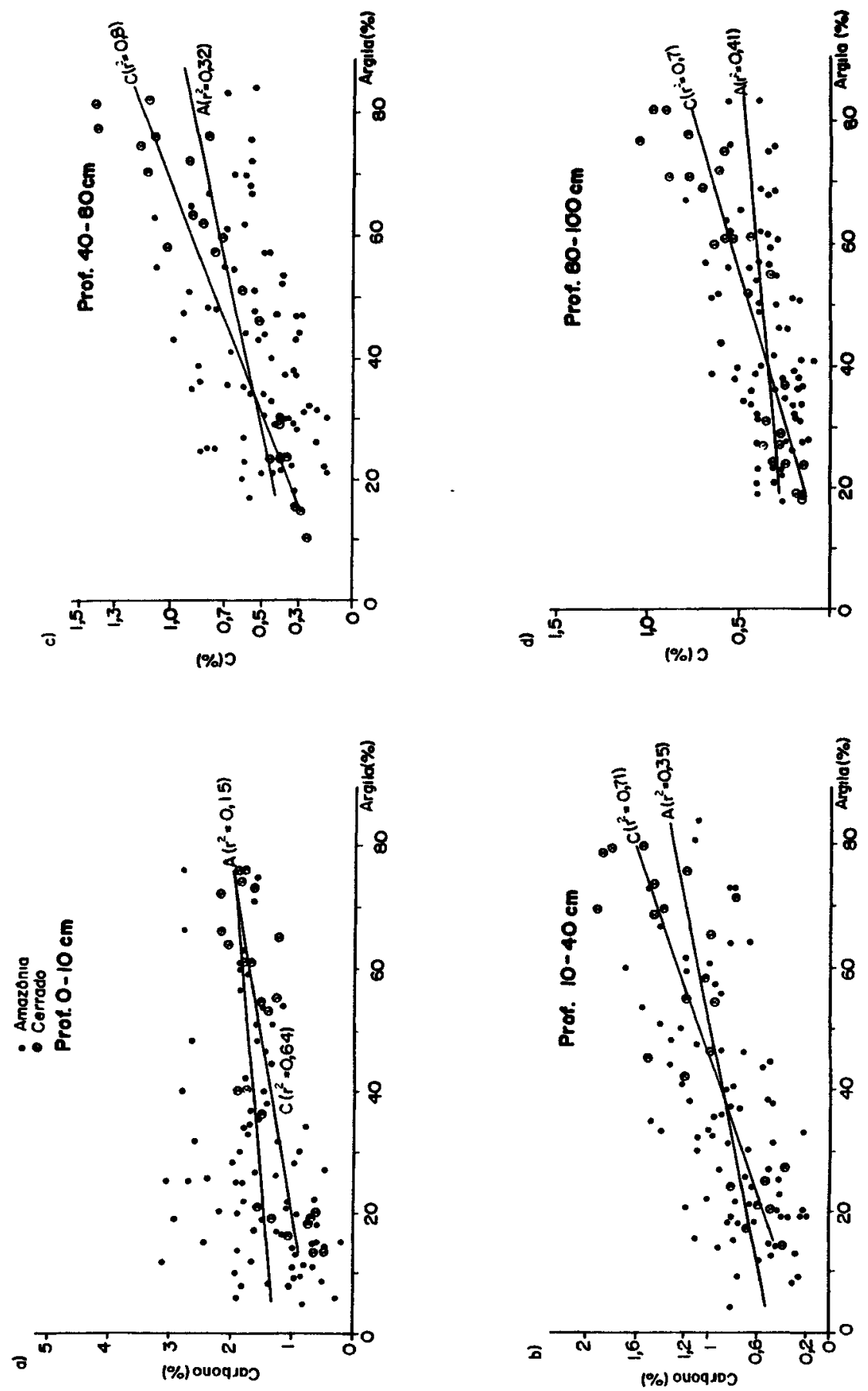

Figura 2 - Relação entre teor de carbono orgânico e teor de argila, de acordo com as profundidades estudadas, a para 0-10; b para 10-40; c para 40-80 e d para 80-100 cm. 

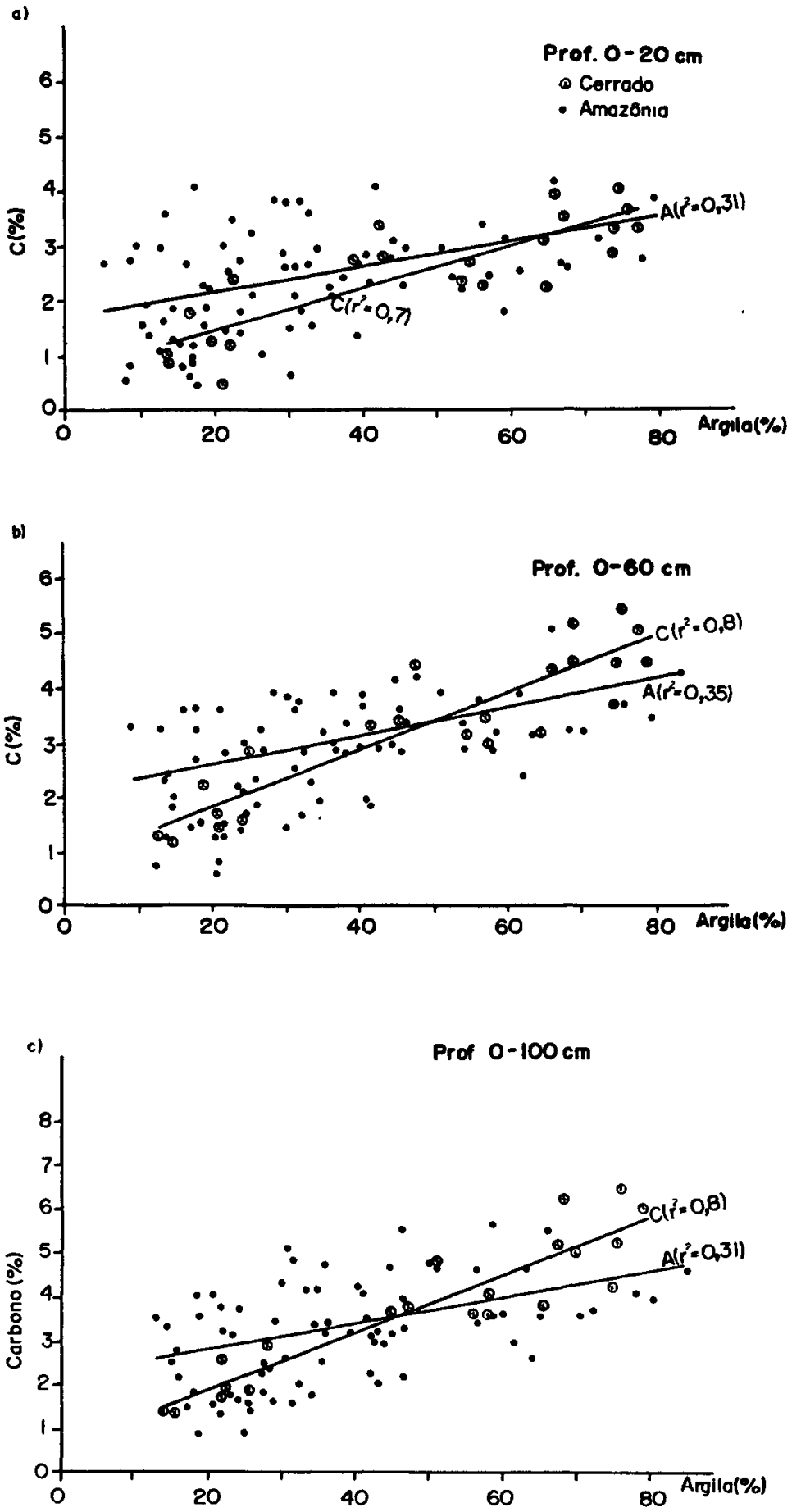

Figura 3 - Relação entre teor de carbono orgânico e teor de argila nas profundidades acumuladas, ou seja, a para profundidade $0-20$; b para $0-60$ e c para todo o perfil até $100 \mathrm{~cm}$. 
Por outro lado, na região de cerrado, os resultados do carbono com a textura dos solos são bem mais consistentes, representados por um $r^{2}$ superior a 0,6 para todas as profundidades. Tal resultado implica numa íntima associação entre carbono orgânico e teor de argila. Além deste fato, foi observado que o teor de carbono orgânico para os solos da região Amazônica, na camada de 0-10 cm (Figura 3a), é maior do que no cerrado, para a faixa de teor de argila até $35 \%$. Porém, à medida que o solo vai ficando mais profundo e argiloso, $o$ teor de carbono orgânico na regiâo do cerrado é superior ao da região Amazônica. Isto se deve ao tipo de vegetação dos dois ambientes e aos valores de $b$ e de $k$. No caso da região Amazônica, a maior fonte de matéria orgânica para o solo é representado principalmente pela adição de folhas, galhos e serapilheira depositados na superfície do solo. A adição pelo sistema radicular não é grande, estando na faixa de 15-20\% (GOLBY et al., 1969), devido provavelmente, ao hábito pivotante das espécies que dominam na região. Portanto, periodicamente está havendo deposição em larga escala na superfície do solo de material orgânico fresco, sem tempo para a humificação, vindo assim explicar o maior teor de carbono orgânico na primeira camada, assim como a grande dispersão dos dados na análise de correlação.

Por sua vez, a vegetação de cerrado é caracterizada por apresentar um substrato graminóide, onde o sistema radicular é abundante, profundo e bem mais homogêneo do que na região Amazônica, haja visto o menor número de espécie por área. Apesar da quantidade de matéria orgânica bruta da área de cerrado, valor b, adicionado anualmente ao solo ser aproximadamente cinco vezes inferior à região Amazônica, o valor da taxa de decomposição do carbono orgânico $\mathbf{k}$, $\epsilon$ mais baixo na região do cerrado. Isto faz com que a matéria orgânica da região de cerrado seja mais estável, em íntima reação com a fração mineral do solo haja visto os elevados valores de $r^{2}$. Por outro lado, a abundância do sistema radicular do substrato graminóide permite a introdução, em profundidade, da matéria orgânica, explicando assim seu maior teor na região do cerrado, quando comparado com a Amazônia.

0 menor valor de $k$ para a região de cerrado, quando comparado com a região Amazônica, pode ser atribuído ao maior teor de oxido de ferro e de alumínio, e, consequentemente, uma mineralogia menos ativa nos 'solos da região do cerrado, além da dominância do regime ústico de umidade. SANCHEZ (1976) tem encontrado valores de $\mathbf{k} \mathrm{em}$ ambiente ústico, inferiores ao ambiente údico de umidade.

Dentro de um mesmo ambiente de vegetação, no caso do Brasil Central, os teores de carbono orgânico para os solos com vegetação de cerrado e cerradão, estão indicados na Figura 4. $\mathrm{Na}$ profundidade de $0-40 \mathrm{~cm}$, o teor de carbono orgânico dos solos com vegetação de cerradão aparenta ser ligeiramente mais elevado do que os solos com vegetação de cerrado. Quando se considera a profundidade total de $100 \mathrm{~cm}$ (Figura 4b), praticamente não há distinção no teor de carbono orgânico. Apesar de ter havido mudança no porte da vegetação na área de cerrado e de cerradão, não houve mudança no substrato graminóide destas regiões, fonte de matéria orgânica, principalmente nos horizontes mais inferiores do solo. Sendo assim, não era de se esperar diferenças no teor de matéria orgânica entre estes solos.

Para o caso da região Amazônica, os solos foram grupados nos latossolos $e$ nos podź́licos vermelho amarelo (TABELA 2). Foi observado que 0 teor de carbono orgânico nos latossolos é ligeiramente superior do que nos PVA. Tal fato pode ser atribuído à mineralogia menos ativa e mais oxídica dos latossolos, o que favorece um menor valor $\mathbf{k}$ e consequentemente, maior concentração de matéria orgânica.

\section{Relação entre o pH e a saturação por bases (Índice V)}

Esta é uma relação muito utilizada na área de fertilidade do solo, indicando que, à medida que o complexo de troca de solo fica mais rico em bases, principalmente o $\mathrm{Ca}$ e o $\mathrm{Mg}, \circ \mathrm{pH}$ sobe.

Para a região de São Paulo, (VAN RAIJ, 1981), os solos num pH entre 6,0 e 6,5 apresenta a faixa de saturação por bases de $65-70 \%$, e num $\mathrm{pH}$ entre 4,0 e 4,5 a faixa de saturação por bases é de $10-20 \%$. No caso da região Amazônica (Figura $5 \mathrm{a}$ ), a $10 \mathrm{~cm}$ de profundidade, a relação destas propriedades é semelhante ao da região de São Paulo.

Em relação a região de cerrados, há sensíveis diferenças nestas propriedades, quando comparados com a região Amazônica, a saber:

- Os solos da região Amazônica são sensivelmente mais ácidos do que a região do cerrado. para um 

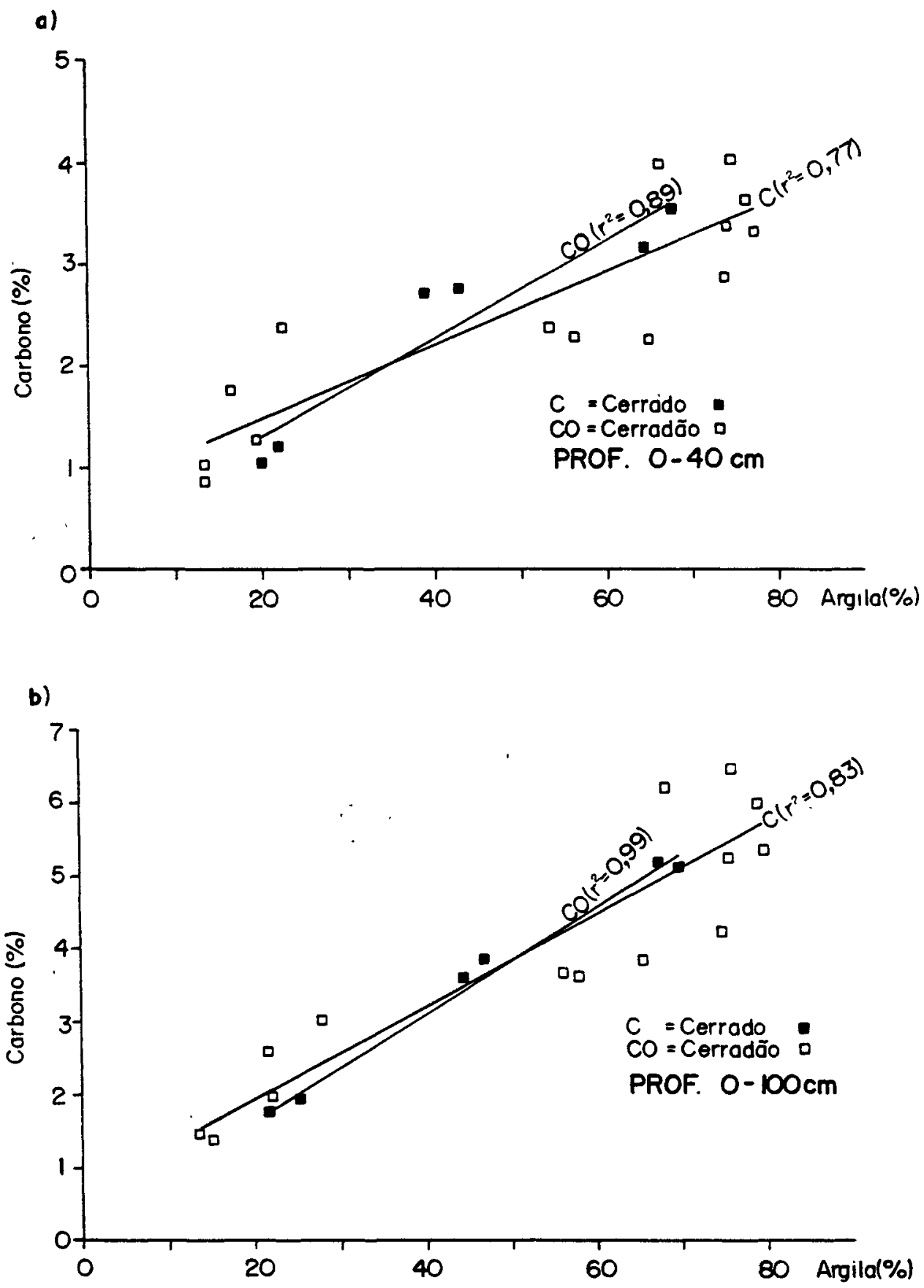

Figura 4 - Distribuição do teor de carbono orgânico nas profundidades $0-40$ e 0-100 cm na vegetação de cerrado e cerradão. 

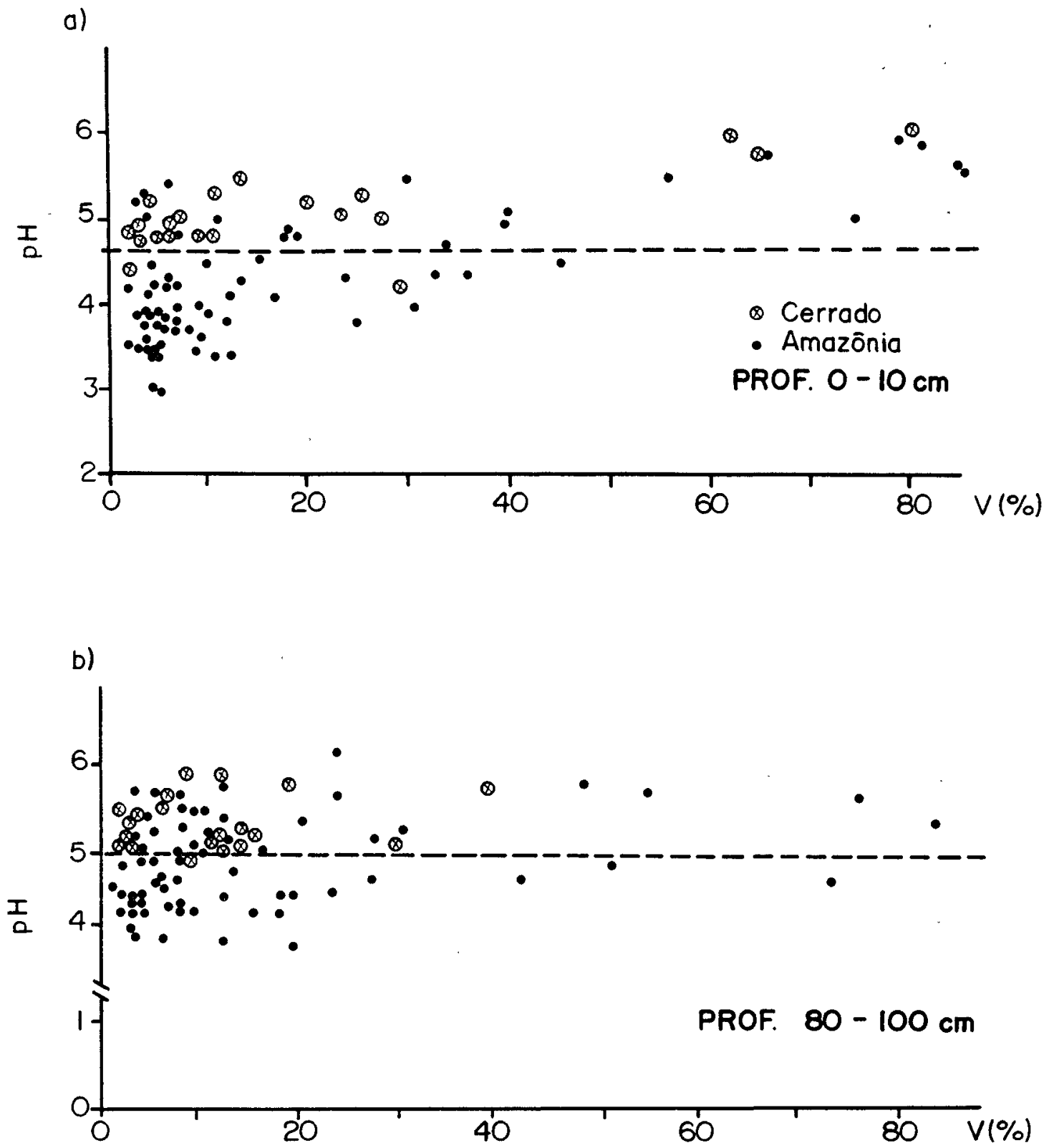

Figura 5 - Relação entre o pH e a saturação por bases entre as regiões Amazônica e Cerrado. a: 0-10 cm de profundidade: $\mathbf{b}: 80-100 \mathrm{~cm}$ de profundidade. 

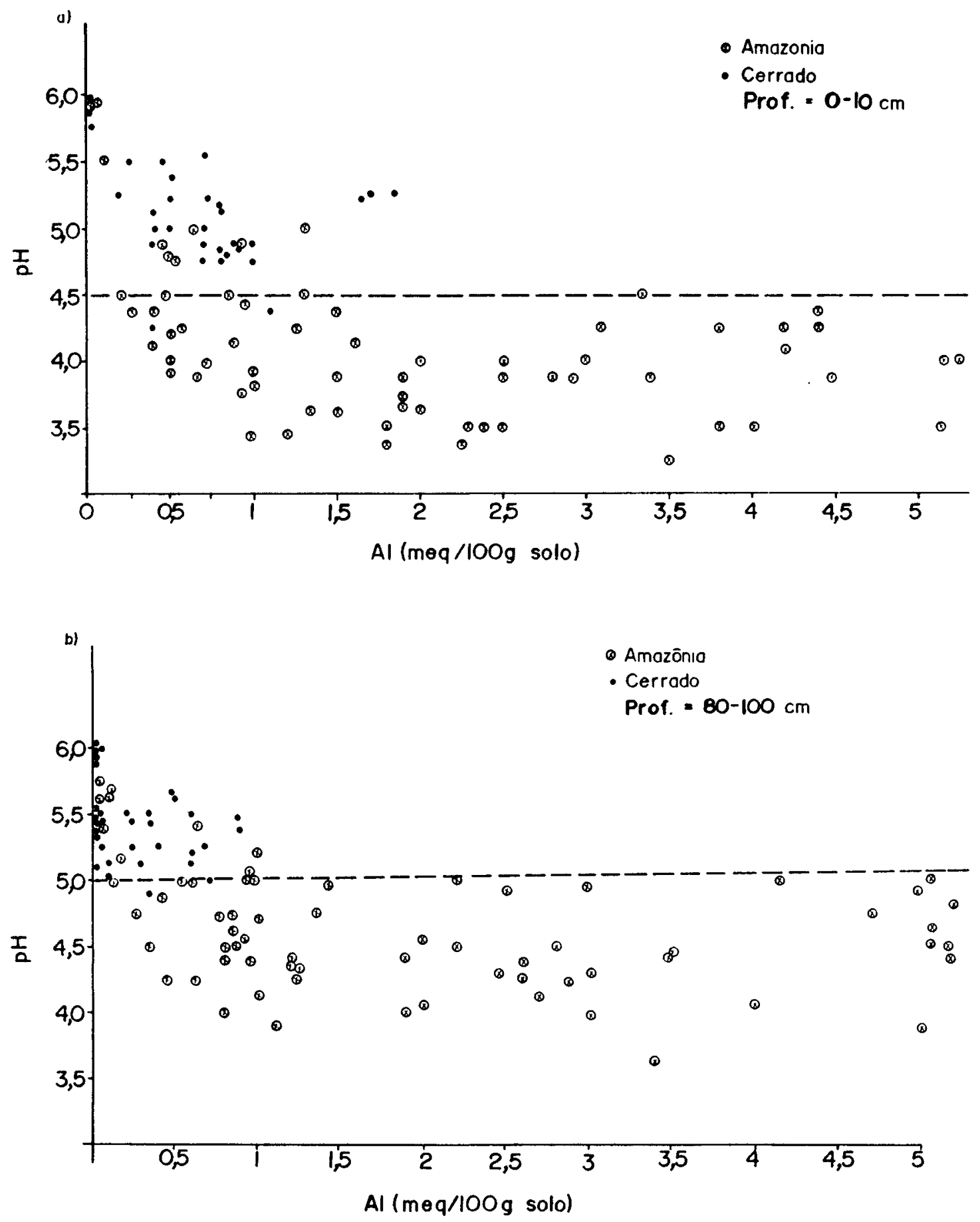

Figura 6 - Relação entre o $\mathrm{pH}$ e o teor de Al trocável em meq/100 g das duas regiões, na camada superficial (a) e na profundidade $80-100 \mathrm{~cm}$ (b). 

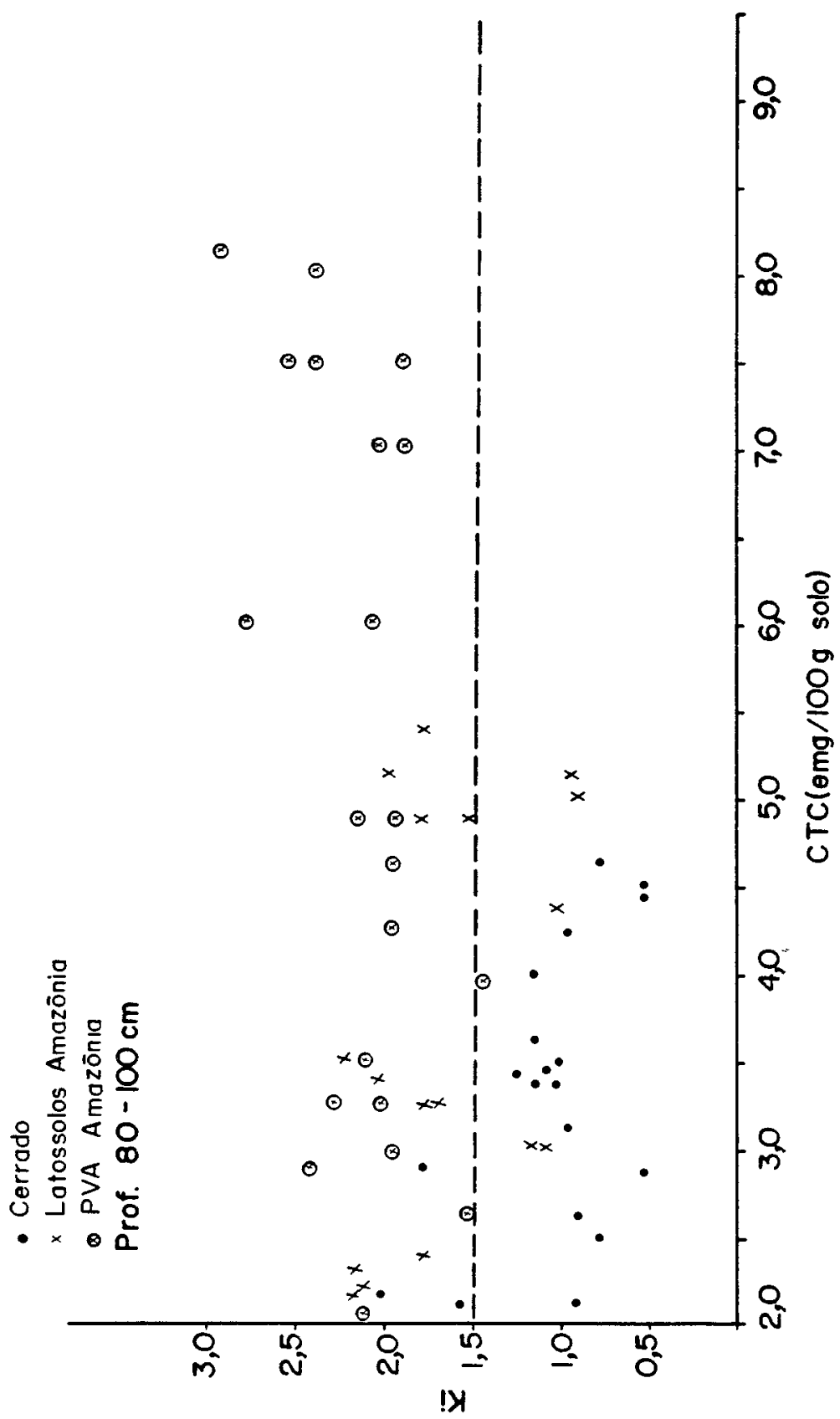

Figura 7 - Relação entre o Ki e a CTC dos solos argilosos das regiões estudadas e entre os latossolos e os PVA da Amazônia na profundidade $80-100 \mathrm{~cm}$. 
mesmo valor de $\mathrm{V}$, digamos, $5 \%$ a $10 \%$ (Figura 5a), o pH dos solos da região Amazônica está em sua quase totalidade, na faixa 3,5 a 4,5 e entre 4,8 a 5,2 , na região do cerrado. Para a mesma faixa de $\mathrm{pH}$, a $80-100 \mathrm{~cm}$ de profundidade (Figura 5b), o pH dos solos da região Amazônica, varia de 4,0 a 5,0, enquanto que no cerrado a variação é de 5,0 a 6,0 .

- Na região do cerrado é possivel encontrar solos com pH próximo a 6,0 (Figura $5 b$ ), porém com $\mathrm{V}$ inferior a $10 \%$, isto é, praticamente sem bases no complexo de troca. Tal resultado é totalmente diferente dos solos de São Paulo, com exceção dos solos ácricos e deve influir no manejo químico destes solos, principalmente no que se refere às práticas de calagem e na demanda de cálcio e magnésio. Explicações para tal fato estão relacionadas à fração mineralógica. $\mathrm{Na}$ região do cerrado, predominam óxidos de $\mathrm{Al}$ e de $\mathrm{Fe}$, tanto na forma cristalina (gibbsita, hematita e goetita), como na forma amorfa. O ponto de carga zero (PCZ) destes minerais está na faixa de $\mathrm{pH} 5,5$ a 6,0 , independente do teor de bases. Vindo a explicar porque um solo com $\mathrm{pH}$ em torno de 6,0 não apresenta $\mathrm{Ca}$ e $\mathrm{Mg}$. Por sua vez, a fração argila de solos da região Amazônica está dominada pela caulinita, cujo PCZ está na faixa de $\mathrm{pH} \mathrm{4,0}$ (JUO, 1980). Sendo assim, haverá necessidade das precações de bases nestes solos para elevar o $\mathrm{pH}$.

\subsection{Relação entre o pH e o teor de Al trocável}

Na região Amazônica, os solos são mais ácidos e o teor de Al trocável mais elevado do que na região de cerrado (Figura 6a). No caso da região do cerrado, na camada superficial, a variação do $\mathrm{pH}$ vai de 4,8 a 6,0 e o teor de $\mathrm{Al}$ trocável raramente ultrapassa $1,0 \mathrm{~m} . \mathrm{eg} / 100 \mathrm{~g}$.

Por outro lado, na região Amazônica, a faixa de pH para esta camada vai de 3,5 a 4,5 e o teor de Al trocável está na faixa de 1,0 a 6,0 m.eg/100g.

Tais diferenças são significativas no que se refere ao manejo químico. $\mathrm{Na}$ região Amazônica, o custo de recuperação química dos solos é bem maior quando comparado ao da região de cerrado, haja visto a maior quantidade de calcário a ser usada. Além do mais, a busca de variedades tolerantes ao $\mathrm{Al}$ trocável parece ser mais viável na região do cerrado, do que na Amazônia.
O maior teor de Al trocável dos solos da região Amazônica se deve a maior CTC, consequência de uma mineralogia da fração argila ser ainda instável para aquelas condições. Enquanto que, na região do cerrado domina minerais mais estáveis, em relação à liberação do Al trocável, como a gibbsita, na região Amazônica domina minerais cauliníticos e alguns de grade 2:1 (vermiculita cloritizada e micas) instáveis e com maior capacidade de liberação de Al.

\section{Relação entre Ki e capacidade de troca catiônica (CTC)}

O $\mathrm{Ki}$ dos solos argilosos da região Amazônica são mais elevados do que da região de cerrado. Enquanto que para a região Amazônica, a faixa do $\mathrm{Ki}$ vai de 1,5 a 2,5, na região do cerrado fica numa faixa mais baixa, entre 0,5 e 1,5 (Figura 7). Os menores valores para o $\mathrm{Ki}$ da região do cerrado, implica, num maior intemperismo quando comparado com a região Amazônica.

Pode-se afirmar que os solos da região Amazônica são bem menos intemperizados. Outro aspecto a ser considerado, se refere aos valores da CTC para um mesmo valor da CTC (sem a contribuição da matéria orgânica), digamos $3 \mathrm{~m} . \mathrm{cg} / 100 \mathrm{~g}$ (Figura 7), o Ki varia de 0,8 a 2,2. A diferença neste caso se refere ao tamanho dos minerais da fração argila dos solos destas duas regiões.

$\mathrm{Na}$ região do cerrado, o $\mathrm{Ki}$ de 1,0 representa dominância de óxidos, cuja CTC já é baixa por natureza (LOPES, 1983). Entretanto, um Ki de 2,0 representa dominância de caulinita, que, neste caso específico, tem a mesma CTC do óxido, $3 \mathrm{~m} . \mathrm{eg} / 100 \mathrm{~g}$.

Foi observado que a caulinita dos solos da região Amazônica é formada por grandes cristais e portanto de menor CTC (TANAKA et al., 1989), igualando assim como a CTC da região do cerrado.

Dentro da região Amazônica, há diferenças entre os latossolos e os PVA no que se refere ao intemperismo. Observa-se que na Figura 7 ocorrem três áreas distintas relacionadas ao $\mathbf{K i}$. Uma área na região de $\mathrm{Ki}$ igual a 1,0 , onde dominam os latossolos mais intemperizados, outra região de $\mathrm{Ki}$ superior a 2,0 onde dominam os PVA, solos menos intemperizados, e uma região intermediária, onde ocorrem os dois tipos de solo. Alguns solos classificados como latossolos pela equipe do RADAM BRASIL, de Ki na faixa de 2,0 a 2,3, foram enquadrados como cambissolos latossólicos (DEMATTÊ, 1988; PIRES FILHO, 1988). 
LIMA (1979) trabalhando com seis perfis do RADAM BRASIL, designados por Latossolos Amarelos argilosos da região Amazônica, constatou serem dois deles Latossolos Típicos, três cambissolos latossólicos de $\mathrm{Ki}$ na faixa de 2,2 e o quinto perfil foi classificada como cambissolo.

\section{CONCLUSÕES}

Apesar de haver dominância de solos latossólicos nas duas regiões estudadas, ocorrem significativas diferenças entre eles, a saber:

- A região do cerrado apresenta solos mais intemperizados do que a região Amazônica. Em consequência disto, há dominância nos cerrados, de solos de mineralogia caulinítica com contribuição de minerais $2: 1$ da região Amazônica. Apesar disso, a CTC da fração argila dos latossolos da Amazônia, não difere da CTC dos solos do cerrado. Dentro da região Amazônica, os latossolos apresentam $\mathrm{Ki}$ diferenciado, sendo um grupo de solos com Ki na faixa $0,8-1,5$, típico dos latossolos, e um grupo na faixa de 2,0 - 2,2, sendo, provavelmente, cambissolos latossólicos. O grupo dos PVA possue Ki superior a 2,0.

- Os solos da região Amazônica são mais ácidos e apresentam valores de Al trocável, significativamente superiores aos da região do cerrado. Tais resultados têm um reflexo direto no manejo, onde a recuperação química dos solos da Amazônia, é mais cara do que no cerrado.

- Há grande diferença entre a saturação das bases (V) e o pH nos solos das duas regióes. Na região Amazônica, a elevação do $\mathrm{pH}$ segue a elevação da saturação das bases, enquanto que, no cerrado, isto não ocorre principalmente nas camadas inferiores. Em consequência deste dado, o manejo químico em relação à dinâmica das bases, $\mathrm{Ca}+\mathrm{Mg}$, deve ser diferenciada entre as regiões.

- O teor de carbono orgânico dos solos de textura arenosa a média, é sempre relativamente maior nos solos da região Amazônica. Entretanto, para os solos argilosos a muito argilosos, o teor de carbono orgânico é sempre mais elevado na região de cerrado, independentemente da profundidade. Não houve diferenças significativas entre o teor de carbono orgânico dos solos com vegetação de cerrados e cerradão. Por outro lado, o teor de carbono orgânico dos latossolos da região Amazônica é mais elevado do que dos PVA.

\section{REFERÊNCIAS BIBLIOGRÁFICAS}

DEMATTÊ, J.L.I. Manejo de solos ácidos dos trópicos úmido da regiāo amazônica. Campinas, Fundação Cargill, 1988. 215p.

EMBRAPA. Levantamento de reconhecimento de média intensidade, avaliação da aptidão agrícola das terras do Triângulo. Serviço Nacional de Levantamento e Conservação de Solos. Boletim de Pesquisa n 1, Rio de Janeiro, 1982a, 526p.

EMBRAPA. Levantamento de reconhecimento de média intensidade, avaliação da aptidão agrícola das terras e indicaçāo de culturas em áreas homogêneas de solos de alguns municípios do Sudoeste do Estado do Mato Grosso. Serviço Nacional de Levantamento e Conservação de Solos. Boletim de Pesquisa n 17, Rio de Janeiro, 1982b, 484p.

EMBRAPA. Levantamento de reconhecimento de média intensidade, avaliação da aptidão agrícola das terras da margem direita do Rio Paraná - Estado de Goiás. Serviço Nacional de Levantamento e Conservação de Solos. Boletim de Pesquisa $n^{0}$ 23, Rio de Janeiro, 1983, 503p.

GREENLAND, D.J.; NYE, P.H. Increases in carbon nitrogen contents of tropical soils under natural fallows. Joumal of Soil Science, Oxford, v.9, p.284-299, 1959.

GOLLEY, F.B.; McGINNINS, J.T.; CLEMENTS, R.J. The structure of tropical forest of Panama and Colombia. Biology Science, v.19, p.693-696, 1969.

JUO, A.S.R. Mineralogical characteristics of alfisols and ultisols. In: THENG, B.K.G., (Ed.). Soils with variable charge. Palmerston North, New Zeland Society of Soil Science, 1980. p.69-86.

LEPSCH, I.F. Influência do cultivo de Eucalyptus e Pinus nas propriedades químicas de solos sob cerrado. Revista Brasileira de Ciência do Solo, v.4, p.103$107,1980$.

LIMA, A.C. Características de latossolos amarelos da Amazônia brasileira. Piracicaba, 1988. 142p. Dissertaçāo (Mestrado) - Escola Superior de Agricultura "Luiz de Queiroz" - Universidade de São Paulo. 
LOPES, A.S. Solos sob "cerrado": características, propriedades e manejo. Piracicaba, POTAFÓs, 1983. 162p.

MALAVOLTA, E.; KLIEMANN, H.J. Desordens nutricionais no cerrado. Piracicaba, POTAFós, 1983. 136p.

PIRES FILHO, A.M. Characterization, classification and use interpretation of a sequence of soils along the Transamazon highway, of Brazil between the Xingu and Jacaré Rivers. Michigan, 1988. 102p. (M.S. Thesis. Michigam State University).

PROJETO RADAM BRASIL. Folha NA 20 - Boa Vista e parte das folhas NA 21 - Tumucumague, NB 20 Roraima e NB 21. Rio de Janeiro, DNPM, 1975. 427p. (Levantamento de Recursos Naturais, 8).

PROJETO RADAM BRASIL. Folha SA 1 - Santarém. Rio de Janeiro, DNPM, 1976. 510p. (Levantamento de Recursos Naturais, 10).

PROJETO RADAM BRASIL. Folha SC - Rio Branco. Rio de Janeiro, DNPM, 1976. 458p. (Levantamento de Recursos Naturais, 12).

PROJETO RADAM BRASIL. Folha SA 19 - Içá. Rio de Janeiro, DNPM, 1977. 446p. (Levantamento de Recursos Naturais, 14).

PROJETO RADAM BRASIL. Folha SC 20 - Porto Velho. Rio de Janeiro, DNPM, 1978, 663p. (Levantamento de Recursos Naturais, 16).
PROJETO RADAM BRASIL. Folha SC 21 - Juruena. Rio de Janeiro, DNPM, 1980. 460p. (Levantamento de Recursos Naturais, 20).

PROJETO RADAM BRASIL. Folhas SC 22 - Tocantins. Rio de Janeiro, DNPM, 1981. 475p. (Levantamento de Recursos Naturais, 22).

SANCHEZ, P.A. Properties and management of soils in the tropics. New York, John Wiley, 1976, 618p.

SERRĀO, E.A.S.; FALESI, I.C.; VEIGA, J.B.; TEIXEIRA, J.F. Productivity of cultivated pastures in low fertility soils of the Amazon of Brazil. In: SANCHEZ, P.A.; TERGAS, L.E. Pasture production in acid soils of the tropics. Cali, CIAT, 1979. p.195-226.

TANAKA, A.: SAKUMA, T.; OKAGAWA, N. The oxisol ultisol area of the Amazon river system. Sapporo, Faculty of Agriculture, Hokkado University. 1989,105 p.

VAN RAIJ, B. Avaliação da fertilidade do solo. Piracicaba. POTAFós, 1981 . 142p.

VIEIRA, L.S.; SANTOS, P.C.J. Amazônia: seus solos e outros recursos naturais. São Paulo, Ed. Agronômica Ceres, 1987, 416p.

Trabalho enviado para publicação em 24.04 .92 Trabalho aceito para publicação em 11.12 .92 